\title{
Building blocks of sexuality
}

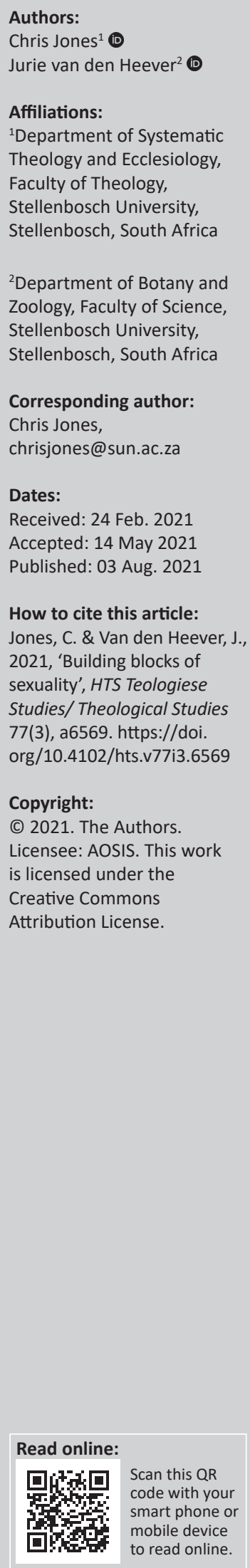

This article broadly discusses the building blocks of sexuality by referring to differences in brain development in the womb, specific genetic factors influencing sex-reversal phenotypes and how they give rise to different sexes and sexual orientations. Gender identity and expression are reviewed, and a practical road map is presented within which religious denominations can responsibly engage with human sexuality, especially samesex lifestyles, within their spheres of influence. Our concerns, discussions and suggestions about this all-important facet of humanity are based on the intellectual richness and research of numerous scientists over an extended period of time in order to point out the most important building blocks of sexuality. Following a qualitative methodological approach, the article starts with the brain differences between men and women as determined in the womb. It is followed by a discussion of the 'five sexes' proposed by Anne Fausto-Sterling, the spectrum of human sexual characteristics and the birth of sexual orientations. The article then looks at bisexuality, gender identity and expression, and before our concluding remarks, at biology and how religion should deal with sexuality, more specifically homosexuality. However, we do not pay attention to animal sexual behaviour, paedophilia, bestiality, gender differences in behaviour and public response to research findings on sexual differentiations in the brain.

Contribution: This article is part of a special collection that reflects on the evolutionary building blocks of our past, present and future. It is not only based on historical thought but also contemporary research. It fits well with the intersectional and interdisciplinary nature of this collection and journal.

Keywords: sexuality; male; female; intersexuality; bisexuality; gender identity and expression; transgender; biology and religion.

\section{Introduction: Brain differences between men and women ${ }^{1}$}

Traditionally it was accepted that humanity consisted of only two sexes, male and female, and although their genders should be considered as equal, men were (and are) in many cultures viewed as superior to women. This will however not be discussed. Moir and Jessel (1989), in their book Brainsex, point out that the sexes are different, not in a typical sociological or cultural sense, but because their brains differ:

The brain, the chief administrative and emotional organ of life, is differently constructed in men and women; it processes information in a different way, which results in different perceptions, priorities and behaviour. (p. 5)

Until relatively recently the differences between men and women 'have been explained away by social conditioning' such as (Moir \& Jessel 1989):

The expectations of parents, whose own attitudes, in turn, reflect the expectations of society; little boys are told that they shouldn't cry, and that the way to the top depends on masculine assertion and aggression. (p. 5)

For centuries, the different functions between men and women were strengthened and refined with reference to our evolution, reflected by our civilisation and enforced by our religion and education. Not much attention was given to the biological fact that we are who we are largely because of the way we develop in the womb. In light of scientific research, the abundance of

1. For more information, see the influential American Psychological Association's statement on paedophilia and the DSM apa.org/news/press/releases/2013/10/pedophilia-mental. See Navarro and Tewksbury (2015) on bestiality: https://www.researchgate. net/publication/282844608 Bestiality An_Overview and Analytic Discussion. For information on gender differences in behaviour and public response to research findings on sexual differentiations in the brain, see Swaab 2018:78-80, 85-87, 92-101.

Note: Special Collection: Challenging Building Blocks, sub-edited by Chris Jones (Stellenbosch University) and Juri van den Heever (Stellenbosch University). 
biological evidence currently totally overshadows sociological and 'political' argument(s). Furthermore, it is not only our hormones that determine who we are and make us behave in specific ways, but 'the interplay between those hormones and the male or female brains, pre-wired specifically to react with them' (see later) (Moir \& Jessel 1989:6).

However, let us take a quick step back in history for a moment. The first systematic tests that explored sex differences between men and women were conducted by Francis Gatton ${ }^{2}$ at the South Kensington Museum in London in 1882. This was followed up by studies in the United States, by Havelock Ellis's Man and Woman published in 1894 . Then in the 1960s came the development of new scientific research into the brain (Couples Guide 2018-2020:n.p.). Today there is no argument anymore within the scientific community that brain differences exist between men and women. These vast number of differences are caused by hormones that 'determine the distinct male or female organisation of the brain as it develops in the womb' (Moir \& Jessel 1989:19). Moir and Jessel (1989) reason that we:

[S]hare the same sexual identity for only the first few weeks after conception. Thereafter, in the womb, the very structure and pattern of the brain begins to take a specifically male or female form. Throughout infant, teenage, and adult life, the way the brain was forged will have, in subtle interplay with the hormones, a fundamental effect on the attitudes, behaviour, and intellectual and emotional functioning of the individual. (pp. 19-28)

This conviction is asserted by many neuroscientists and researchers. American neurologist Restak (1979, as quoted by Moir \& Jessel 1989; Pearsall 2001:72) reasons:

It seems unrealistic to deny any longer the existence of male and female brain differences. Just as there are physical dissimilarities between males and females ... there are equally dramatic differences in brain functioning. (p. 20)

We have made giant progress in recent years regarding how the brain works, and we have discovered that - biologically and behaviourally - we are what we are.

'About six or seven weeks after conception' the foetus (Moir \& Jessel 1989):

[M]akes up its mind and the brain begins to take on a male or female pattern. What happens, at that critical stage in the darkness of the womb, will determine the structure and organisation of the brain: and that, in turn, will decide the very nature of the mind. It is one of the most fascinating stories of life and creation; a story largely unknown, but now, at last, beginning to unfold in its entirety. (p. 21)

Our genes carry the coded blueprint of our unique characteristics. Men and women are different in every one of our bodily cells, because 'every fibre of our being has a different set of chromosomes within it, depending on 2.Read more about Gatton's tests and Ellis's studies: https://couples.guide/about/a bit-history-about-brain-research/ whether we are male or female' (Moir \& Jessel 1989:21). Moir and Jessel (1989) explain that our:

[I]dentity blueprints come in the form of forty-six chromosomes, half contributed by the mother, half by the father. The first fortyfour team up with one another, forming pairs of chromosomes which determine certain bodily features of the eventual individual, such as the colour of the eyes, the length and shape of the nose. But the last pair is different. (p. 21)

We know (Moir \& Jessel 1989, see Gellatly 2009; Rahman \& Pang 2020; Shettles 1960) that the mother:

$[C$ ]ontributes an ' $X$ ' chromosome to the egg ... If the father's contribution on fertilisation of the egg is another ' $X$ ' chromosome, the outcome will - normally - be the formation of a girl baby. If the father's sperm contains a ' $Y$ ' chromosome, normally a baby boy will be born. (p. 22)

Graves (2017), in her article 'The genetic differences between men and women could be greater than we thought', says in this regard:

That beyond just genes on $X$ and $Y$, a full third [more than 6500 genes] of our genome is behaving very differently in men and women. These new data ${ }^{3}$ pose challenges for science, medicine and maybe even gender equity. (n.p.)

Referring to the study by Gershoni and Pietrokovski (2017, see footnote 2), Graves (2017) states that many:

[G]enes were far more active in one sex or the other. A few of these genes showed sex biased activity in every tissue of the body. More commonly, the difference was seen in one or a few tissues. Most of these genes were not on sex chromosomes: only a few lay on the $Y$ or the $X$. How could a third of our genes be differently controlled in men and women? We now understand that proteins work in extensive networks. Change the amount of one protein produced by one gene, and you change the amounts of all the proteins produced by many genes in a long chain of command. We also know that hormones have powerful influences on gene activity. For instance, testosterone and oestrogen dial up or down many genes in reproductive and body tissues. (n.p.)

According to Graves (2017) a study by Trabzuni et al. (2013) confirms that:

[S]ome sex biased genes were involved in brain function, reopening the debate about differences in male and female behaviour ... Like it or not, evidence now shows that men and women differ genetically far more profoundly that we have previously recognised. (n.p.)

Thus far we have referred to only two sexes, male and female, but research indicates that we should be reflecting on five, at least, and perhaps even more.

\section{The five sexes of Fausto-Sterling}

To understand why male and female are not enough, we should turn to the word intersexuality.

3. See https://bmcbiol.biomedcentral.com/articles/10.1186/s12915-017-0352-z

4. See https://doi.org/10.1038/ncomms3771 
Intersexuality ' $[d]$ escribes a person whose biological sex is ambiguous. There are many genetic, hormonal, or anatomical variations that can make a person's sex ambiguous' (San Francisco Human Rights Commission's Lesbian, Gay, Bisexual, Transgender [LGBT] Advisory Committee 2011:37). Intersexual people, or to use the older term hermaphrodites, appear from the earliest times in stories about human origin. 'Early biblical scholars believed Adam began life as a hermaphrodite' (Fausto-Sterling 1993:23). According to them Adam later changed or divided into two people - one male and one female. Plato also believed that there once were three sexes (male, female and hermaphrodite), 'but the third sex was lost with time' (Fausto-Sterling 1993:23). In the Talmud and the Tosefta, the Jewish books of the law, an extensive list of regulations is given for people of mixed sex such as that hermaphrodites are expressly forbidden to inherit estates from their father, to seclude themselves with women or to shave. When hermaphrodites menstruated, they had to isolate themselves from men, and they could not serve as witnesses or priests. However, 'the laws of pederasty applied to them' (Fausto-Sterling 1993:23).

In her article 'The five sexes: Why male and female are not enough', developmental geneticist Fausto-Sterling (1993) starts with the following intriguing story:

In 1843 Levi Suydam, a twenty-three-year-old resident of Salisbury, Connecticut, asked the town board of selectmen to validate his right to vote as a Whig in a hotly contested local election. The request raised a flurry of objections from the opposition party, for reasons that must be rare in the annals of American democracy: it was said that Suydam was more female than male and thus (some eighty years before suffrage was extended to women) could not be allowed to cast a ballot. To settle the dispute a physician, one William James Barry, was brought in to examine Suydam. And, presumably upon encountering a phallus, the good doctor declared the prospective voter male. With Suydam safely in their column the Whigs won the election by a majority of one.

Barry's diagnosis, however, turned out to be somewhat premature. Within a few days he discovered that, phallus notwithstanding, Suydam menstruated regularly and had a vaginal opening. Both his/her physique and his/her mental predisposition were more complex than was first suspected. S/ he had narrow shoulders and broad hips and felt occasional sexual yearnings for women. Suydam's 'feminine propensities, such as a fondness for gay colors, for pieces of calico, comparing and placing them together, and an aversion for bodily labor, and an inability to perform the same, were remarked by many'. Barry later wrote: It is not clear whether Suydam lost or retained the vote, or whether the election results were reserved. (pp. 20-21)

As already indicated, in Western culture we were/are committed to the notion that there are only two sexes, but, according to Fausto-Sterling (1993), we are dealing with at least five sexes.

We cannot maintain a two-party sexual system anymore, because, if we do, we will be in defiance of nature. For:
[B]iologically speaking, there are many gradations running from female to male; and depending on how one calls the shots, one can argue that along that spectrum lie at least five sexes - and perhaps even more. (p. 21)

The concept of the intersexual body, as indicated in Figure 1, has been recognised for many years. The word is used as an umbrella term for three major subgroups with a mixture of male and female characteristics (Fausto-Sterling 1993):

[T] he so-called true hermaphrodites ... who possess one testis and one ovary (the sperm- and egg-producing vessels, or gonads); the male pseudohermaphrodites ... who have testes and some aspects of the female genitalia but no ovaries; and the female pseudohermaphrodites ... who have ovaries and some aspects of the male genitalia but lacks testes. (p. 21)

Each of these categories is complex, and the percentage of male and female characteristics can vary tremendously amongst members of the same subgroup. Although there is a lot of uncertainty, for example about their needs, problems, attractions and repulsions, one can in light of what we know about these subgroups refer to them as separate sexes in their own right: 'herms' (named after true hermaphrodites), 'merms' (male pseudohermaphrodites) and 'ferms' (female pseudohermaphrodites) (FaustoSterling 2000:19). Understandably, some people find this scientific information deeply disturbing, whilst others find it extremely liberating.

In some true hermaphrodites the 'testes and the ovary grow separately but bilaterally; in others they grow together within the same organ, forming an ovo-testis' (Fausto-Sterling 2000:22). Normally 'at least one of the gonads functions quite well, producing either sperm cells or eggs, as well as functional levels of the sex hormones - androgens or oestrogens' (Fausto-Sterling 2000:22).

\section{In 2017 the United Nations ${ }^{5}$ (Intersex n.d.) confirmed that:}

[I]ntersex people are born with sex characteristics (including genitals, gonads and chromosome patterns) that do not fit typical binary notions of male or female bodies. Intersex is an umbrella term used to describe a wide range of natural bodily variations. In some cases, intersex traits are visible at birth while in others, they are not apparent until puberty. Some chromosomal intersex variations may not be physically apparent at all. According to experts, between $0.05 \%$ and $1.7 \%$ of the population is born with intersex traits - the upper estimate is similar to the number of red haired people. Being intersex relates to biological sex characteristics, and is distinct from a person's sexual orientation or gender identity. An intersex person may be straight, gay, lesbian, bisexual or asexual, and may identify as female, male, both or neither. Because their bodies are seen as different, intersex children and adults are often stigmatized and subjected to multiple human rights violations, including violations of their rights to health and physical integrity, to be free from torture and ill-treatment, and to equality and nondiscrimination. (p. 1)

5.For more information see 'Intersex': https://www.unfe.org/wp-content/ uploads/2017/05/UNFE-Intersex.pdf 

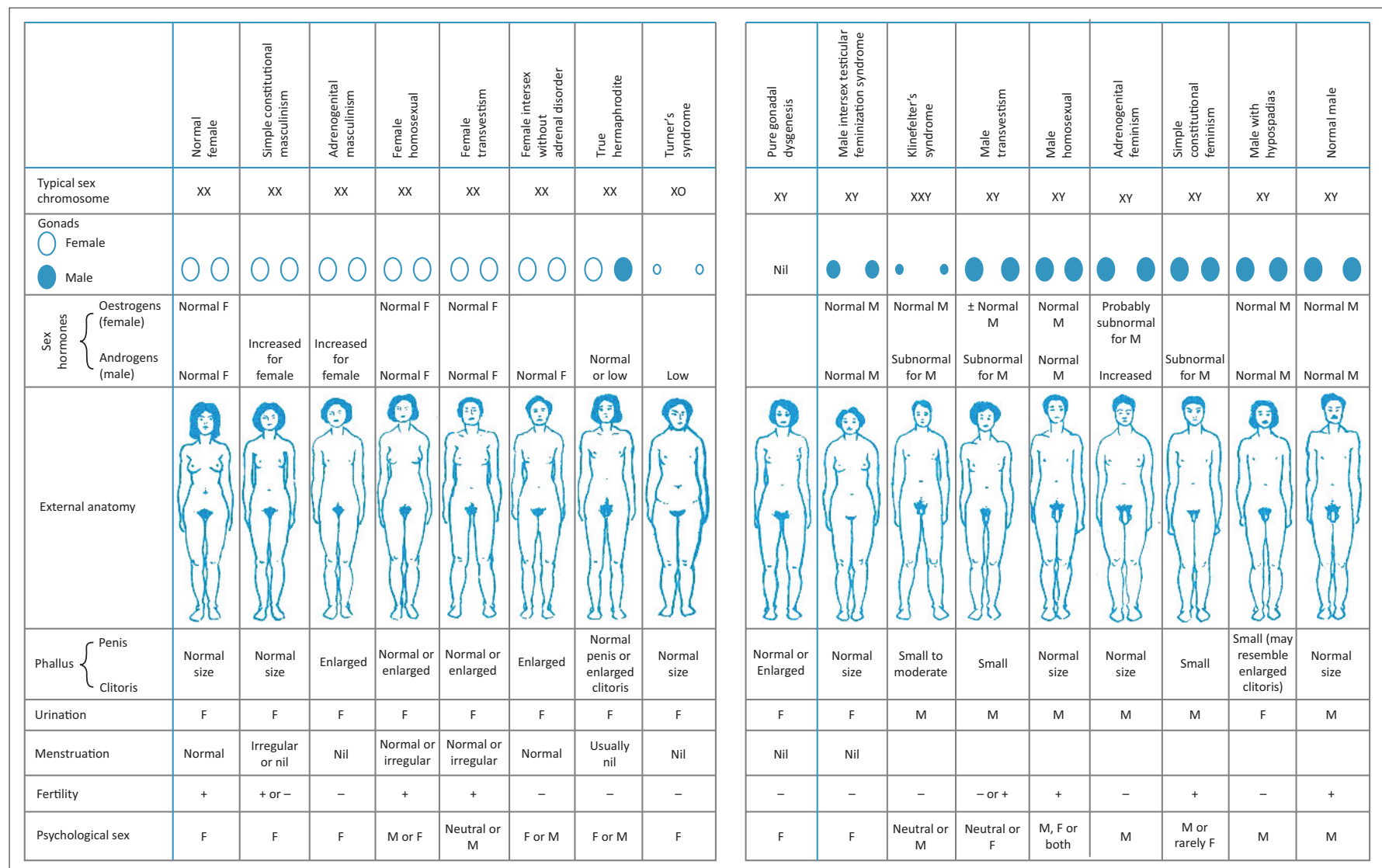

Source: Jost, A.D., 1971, 'Development of sexual characteristics', in Human reproduction, From the Science Journal, Special Issue, June 1970, pp. 104-105, Paladin, London.

Note: Only two sexes, male and female, are recognised in ordinary life. However, psychologists have long believed that there is a spectrum of sexual types between the normal male and the normal female. This scheme by C. N. Armstrong is one interpretation showing the relationship between genetic, psychological and hormonal factors used in determining the sex of an individual.

FIGURE 1: Spectrum of human sexual characteristics by C.N. Armstrong.

With regards to physical integrity, ${ }^{6}$ it has (Intersex n.d.):

$[B]$ ecome common practice to subject intersex children to unnecessary surgical and other procedures for the purpose of trying to make their appearance conform to binary sex stereotypes. These often irreversible procedures can cause permanent infertility, pain, incontinence, loss of sexual sensation, and lifelong mental suffering, including depression. Regularly performed without the full, free, and informed consent of the person concerned, who is frequently too young to be part of the decision-making, these procedures may violate their rights to physical integrity, to be free from torture and ill-treatment, and to live free from harmful practices. Such procedures are frequently justified on the basis of cultural and gender norms and discriminatory beliefs about intersex people and their integration into society. (p. 1)

Attitudes that discriminate against intersex people such as in access to health services, education, public services, employment and sports cannot (Intersex n.d.):

[J]ustify ... forced treatment and violations of the right to physical integrity. States have a duty to combat harmful stereotypes and discrimination, rather than reinforcing them. Such procedures may sometimes also be justified on the

6. Read Cheryl Chase's talk titled. "Sexual ambiguty: The patient-centered approach" which is a critique on 'corrective' surgery on infants born with ambiguous genitalia (she herself lives with the consequences of such surgery): http://www2.kobe-u. (she herself lives with the consequences of such surgery): http://www2.kobe-u.
ac.jp/ alexroni/IPD\%202015\%20readings/IPD\%202015_4/FAUSTO_STERLINGac.jp/ alexroni/IPD\%202015\%20readings/IPD\%202015_4/FAUSTO_STERLIN basis of alleged health benefits, but these are often proposed on the basis of weak evidence and without discussing alternative solutions that protect physical integrity and respect autonomy. (p. 1)

Unfortunately, these kinds of beliefs and pressure from societies (Intersex n.d.):

$[A]$ re often reflected by doctors, as well as parents of intersex children, who may encourage and/or give their agreement to such procedures, despite the lack of medical indication, necessity or urgency, and despite the fact that such procedures may violate human rights standards. Agreement is frequently given in absence of information on the short- and long-term consequences of such surgery and lack of contact with peers, including intersex adults and their families. Many intersex adults exposed to such surgery as children emphasize the shame and stigma linked to attempts to erase their intersex traits, as well as significant physical and mental suffering, including as a result of extensive and painful scarring. Many also feel that they were forced into sex and gender categories that do not fit them. Given their irreversible nature and impact on physical integrity and autonomy, such medically unnecessary, unsolicited surgery or treatment should be prohibited. Intersex children and their families should receive adequate counselling and support, including from peers. (p. 1)

There are still many people, cultures and religions that have yet to come to grips with 'the ancient and relatively 
uncomplicated reality of homosexual love' (Faust-Sterling 1993:24) and will therefore 'not readily embrace intersexuality' (Fausto-Sterling 1993:24). Although the older terms for intersexuality are used in this article, they are being replaced by most experts, patients and families. 'Increasingly, this group of conditions is being called disorders of sex development (DSDs)' (MedlinePlus 2021:n.p.). This term is reckoned to be more accurate and less stigmatising than the term intersex.

However, progress has been made over the last decades with regards to intersexuality. In 2019, the BBC News (2019) reported that intersexuality must be seen separate:

[F]rom a person's gender identity or sexual orientation. But many face stigma, legal discrimination or even forced surgery because of these characteristics. Germany previously allowed intersex people to opt out of choosing either male or female as a gender in 2013. But in $2017^{7}$ the country's top court ruled it was discrimination to deny people a gender, after a person registered as female had a chromosome test confirming they were neither sex. (n.p.)

On 01 January 2019, Germany 'adopted intersex identity into law' (BBC News 2019:n.p.). This implies that 'intersex people can register themselves as such on birth certificates, passports and other official documents' (BBC News 2019). This report further states that:

[I]ntersex people ... who do not fit the biological definition of male or female can now choose the category 'diverse' on official documents. Those choosing the option will need a doctor's certificate to register ... Other countries [too] have approved laws in recent years to help recognise intersex people. Austria's constitutional court made a similar ruling to Germany's in June [2018], while Australia, New Zealand, Malta, India and Canada have all passed measures to redress issues facing intersex citizens. (n.p.)

What has become clear since the 1990s is that 'society has moved beyond [three and even] five sexes to a recognition that gender variation is normal and, for some people, an arena for playful exploration' (Fausto-Sterling 2000:22). However, psychologist Suzanne Kessler (1998), in her book Lessons from the Intersexed, discusses Fausto-Sterling's 'five sexes' proposal as she dealt with it in 1993 and reasons that it:

$[S]$ till gives genitals ... primary signifying status and ignores the fact that in the everyday world gender attributions are made without access to genital inspection ... What has primacy in everyday life is the gender that is performed, regardless of the flesh's configuration under the clothes. (p. 121)

In her article 'The five sexes, revisited', Fausto-Sterling (2000) deals with this critique by agreeing with Kessler. She says that it:

[W]ould be better for intersexuals and their supporters to turn everyone's focus away from genitals. Instead, as she [Kessler] suggests, one should acknowledge that people come in an even wider assortment of sexual identities and characteristics than mere genitals can distinguish. (p. 22)

7.For more information see: https://www.bbc.com/news/world-europe-41912754

\section{According to Ainsworth (2015):}

$[Y]$ et if biologists continue to show that sex is a spectrum, then society and state will have to grapple with the consequences, and work out where and how to draw the line. Many transgender and intersex activists dream of a world where a person's sex or gender is irrelevant. (p. 291)

Promulgating legislation formalising sexuality as a broad spectrum with unbounded options may not yet have the desired effect but will go a long way in the right direction. According to Eric Villian, clinician and director of the Center for Gender-Based Biology at the University of California, Los Angeles, as quoted in Ainsworth (2015):

$[M] y$ feelings is that since there is not one biological parameter that takes over every other parameter, at the end of the day, gender identity seems to be the most reasonable parameter. (p. 291)

In the words of Ainsworth (2015:291): 'In other words, if you want to know if someone is male or female, it may be best to just ask.'

Having discussed the different sexes, and how they are formed in the womb, we can turn to the origin of different sexual orientations.

\section{The birth of difference}

We have seen above how baby girls and boys, as well as intersexual people, are born. It is a highly complex process, and no blueprints are guaranteed. We know that the genes alone 'do not guarantee the sex of a child' (Moir \& Jessel 1989:22). According to Moir and Jessel (1989):

$[T]$ hat depends on the intervention, or the absence, of the other factor in sex determination - the hormones. Whatever the genetic make-up of the embryo, the foetus will only develop as a male if male hormones are present, and it will only develop as a female if male hormones are absent. (p. 22)

Different studies of where development follows an alternative path helped scientists tremendously 'to build a picture of what happens during normal development' (Moir \& Jessel 1989):

These studies have shown that male hormones are the crucial factor in determining the sex of a child. If a female foetus, genetically $\mathrm{XX}$, is exposed to male hormones, the baby is born looking like a normal male. If a male foetus, genetically $\mathrm{XY}$, is deprived of male hormones, the baby is born looking like a normal female. (p. 22)

Moir and Jessel (1989) continue to explain that in the first weeks in the womb:

[T] he tiny foetus isn't noticeably a miniature girl or a miniature boy. It has all the basic equipment, such as vestigial ducts, tracts and so on, to develop as either sex. But as the weeks go by, the genes begin to put the message across. If things go normally, and everything follows the $\mathrm{XY}$ blueprint of a boy, the chromosomes will cue the development of the gonads into testes. (p. 23) 
It is now, around six weeks (Moir \& Jessel 1989):

$[T]$ hat sexual identity is finally determined - when the male foetus develops the special cells which produce the male hormones or androgens, the main one being testosterone. The hormones instruct the body not to bother with developing a feminine set of sexual equipment, while stimulating the development of embryonic male genitalia. (p. 23)

\section{At about the same time (Moir \& Jessel 1989):}

[I]f the baby is female, genetically $\mathrm{XX}$, the reproductive machinery develops along female lines, produces no significant amount of male hormones, and results in a girl baby. Just as the six-week-old foetus wasn't recognisably male or female in appearance, so the embryonic brain takes some time before it begins to acquire a specific sexual identity. If the embryo is genetically female, nothing very drastic happens to the basic pattern of the brain. In broad terms, the natural template of the brain seems to be female. In normal girls it will develop naturally along female lines. (pp. 23-24)

It is different in boys. 'Just as male gender depended on the presence of male hormone, so a radical intervention is needed to change that naturally female brain into a male pattern' (Moir \& Jessel 1989:24). This process is literally mind-altering and 'is the result of the same process that determined those other physical changes - the intervention of the hormones' (Moir \& Jessel 1989:24). Embryonic baby boys:

[A]re exposed to a colossal dose of male hormone at the critical time when their brains are beginning to take shape. The male hormone levels then are four times the level experienced throughout infancy and boyhood. (Moir \& Jessel 1989:24)

At each end of male development, a vast surge of male hormone occurs - at 'adolescence, when his sexuality comes on stream, and six weeks after conception, at the moment his brain is beginning to take shape' (Moir \& Jessel 1989:24).

Swaab (2018:76) confirms that our gender identity, for the rest of our lives, is determined in this period in our brain structure. However, and this is important (Moir \& Jessel 1989):

$[A] \mathrm{s}$ with the development of the rest of the body, things can go wrong. A male foetus may have enough male hormones to trigger the development of male sex organs, but these may not be able to produce the additional male hormones to push the brain into the male pattern. His brain will 'stay' female, so he will be born with a female brain in a male body. In the same way, a female baby may be exposed in the womb to an accidental dose of male hormone ... and end up with a male brain in a female body. (pp. 24-25)

If we do not know that our brains are made differently, 'it is not surprising that we have difficulty in acknowledging, or understanding, each other's differences' (Moir \& Jessel 1989:25). This knowledge came from children who for one or another reason have had an abnormal dose of hormones in the womb and from experiments with animals. Because of limited space, we cannot elaborate on this.
According to Moir and Jessel (1989), in:

$[T]$ he early days of scientific gender curiosity the wisdom was that biology had a comparatively minor influence on our behaviour and attitudes. The assumption was that, in terms of our minds, we were born sexually neutral, our minds a blank slate on which our parents, our teachers, and the expectations our societies had of us would chalk their determinant messages ... [T] oday there are hundreds of cases which show that social conditioning alone cannot determine our sexual mind-set. Many of these cases concern accidents of nature which have resulted in trapping a female brain in a male body, or a male brain in a female one. (p. 29)

These genetic and hormonal influences in the womb not only explain the different sexes but also why some people are gay and others lesbian ${ }^{8}$ and bisexual:

For many years scientists believed that female development was the default programme, and that male development was actively switched on by the presence of a particular gene on the $\mathrm{Y}$ chromosome.

This gene, Sex-determining Region Y (SRY), was discovered in 1990, and on its own can turn the gonad from ovarian to testicular development. $X X$ individuals with a fragment of the $Y$ chromosome containing SRY develop as males. Arnold (2012:1) has presented an interesting adjunct to the universally accepted idea that most sex differences in non-gonadal tissues are the result of specific gonadal secretions, in showing that the sexual phenotypes of specific cells or tissues are also influenced by the sex chromosomes.

This framework recognises the effect of SRY and downstream sex differences in gonadal hormones as the dominant pathway for sex determination of the large majority of nongonadal tissues, but at the same time it recognises multiple primary sex-determining factors not downstream of the gonadal effects of SRY that act in parallel with gonadal differentiation to influence the sex of tissues, including sex differences in the susceptibility to disease.

The challenge for the future is to discover all of the sexdetermining factors on the sex chromosomes and explain the pathway downstream of each, to understand what makes men and women different. This is not just a theoretical question but one of potential significance in medicine.

Genes such as WNT-4 that actively engage in ovarian development have been known since the turn of the century. Jordan et al. (2001:1107) reported that they had '... identified an XY female patient in whom WNT-4 is overexpressed, suggesting that WNT-4 is a sex-determining gene in humans.'

\section{According to Ainsworth (2015):}

$X Y$ individuals with extra copies of this gene can develop atypical genitals and gonads, and a rudimentary uterus and Fallopian tubes. In 2011 researchers showed that if another key ovarian gene, R-Spondin 1 (RSPO1), is not working normally, it causes XX people to develop an ovotestis - a gonad with areas of

8.We have numerous structural and functional brain differences associated with our sexual orientation, and these originate in the womb, as discussed above. For more sexual orientation, and these originate in the womb, as discussed above. For more
information see: (1) Kinsey et al. (1948), (2) Swaab and Hofman (1990), (3) LeVay (1991) and (4) Allen and Gorski (1992). 
both ovarian and testicular development ... Changes in the activity or amounts of molecules (such as WNT-4) in the networks can tip the balance towards or away from the sex seemingly spelled out by the chromosomes. (p. 289)

Subsequently Zhao et al. (2017) pointed out that:

$[T]$ he sexual differentiation paradigm contends that the female pattern of the reproductive system is established by default because the male reproductive tracts (Wolfian [sic] ducts) in the female degenerate owing to a lack of androgen. (p. 717)

Their research has shown that the degeneration of the incipient male reproductive tract in embryos is not a passive process because androgens are absent but an active process resulting from the presence of the nuclear receptor COUPTFII (chicken ovalbumin upstream promoter transcription factor II). In addition, they discovered that female mouse embryos lacking COUP-TFII in the tissue of the wolffian ducts developed as intersex, with both male and female reproductive tracts present.

\section{Bisexuality ${ }^{9}$}

According to the American Psychological Association (APA), the term bisexual person 'is used to describe a person who experiences emotional, romantic and/or sexual attractions to, or engages in romantic or sexual relationships with, more than one sex or gender' (APA 2021:n.p.).

The National Health Statistics Reports (Copen, Chandra \& Febo-Vazquez) stated in 2016:

[T]hat 1.3 percent of women and 1.9 percent of men said they were 'homosexual, gay, or lesbian', and that 5.5 percent of women and 2 percent of men said they were bisexual. (p. 1)

In this regard it is important to keep in mind that what people say about themselves and who they really are sometimes (often?) differ. The APA (2021) reasons that:

$[T]$ hese findings indicate that bisexual people may comprise the largest single group in the LGB community for both women and men. Nevertheless, many believe that bisexuality does not really exist, and bisexual people suffer bi-invisibility ${ }^{10}$ or erasure and bi-negativity ${ }^{11}$ from both the lesbian and gay community and the heterosexual community, which may explain evidence suggesting higher rates of health disparities bisexuals experience compared to either. (n.p.)

According to the San Francisco Human Rights Commission's LGBT Advisory Committee (2011), bisexuality refers to an:

$[I]$ ndividual whose enduring physical, romantic, emotional, and/or spiritual attraction is to people of more than one

9.For further reading and understanding see: (1) https://www. pewsocialtrends. org/2013/06/13/chapter-3-the-coming-out-experience/; (2) https://www.lgbtmap. org/lgbt-movement-overviews/understanding-issues-facing-bisexual-americans $\% 20$; (3) https://www.tandfonline.com/eprint/3qhtss57x68Q9ypgNqYT/full.

10.For more information see: https://sf-hrc.org/sites/default/files/Documents/HRC Publications/Articles/Bisexual_Invisiblity_Impacts_and_Recommendations_ March_2011.pdf

11.For further reading: https://biresource.org/wp-content/uploads/2016/11/Mental_ Health_Biphobia_Brochure.pdf sex/gender. While some people call themselves pansexual or omnisexual, these terms should be avoided unless quoting someone who self-identifies that way. (p. 35)

There are also other variations such as gender-fluid and ambisexual.

\section{Gender identity and expression}

Gender identity refers to one's 'internal, personal sense of being male, female, or third-gender. For transgender and third-gender people, their birth-assigned sex and their own internal sense of gender identity do not match', whilst gender expression refers to the '[e]xternal manifestation of one's gender identity, usually expressed through "masculine," "feminine," or gender-variant behavior (including interests and mannerisms), clothing, haircut, voice, or body characteristics' (San Francisco Human Rights Commission's LGBT Advisory Committee (2011:36). Transgender is an:

$[U]$ mbrella term for people whose gender identity and/or gender expression differs from the sex they were assigned at birth. Transgender people may or may not choose to alter their bodies hormonally and/or surgically. The term may include but is not limited to transsexuals, ${ }^{12}$ third-gender/genderqueer people, cross-dressers, and other gender-variant people. (p. 40)

Through the ages religion played an important role in how people perceived sexuality and sexual orientation. Consequently, we will now turn to biology and religion's understanding (with focus on Christianity) of the complexity of sexuality.

\section{Biology and religion ${ }^{13}$}

Knowledge and exposure empower and liberate. We have seen this in recent years, especially when it comes to sexuality. Modern science is increasingly entering areas of the world of human experience that were previously held up as the exclusive domain of faith and where evolutionary biology in particular has been considered incompetent as an explanatory model. The latest research on the construction and functioning of the human brain points out and underlines the fact that the brain, like the lungs or the heart, is one of the organs of the body and not some invisible entity accommodating a soul or spirit.

We are our physical bodies and experience the world in all its facets through the physical. After all, religion cannot be practised without the body. Evolutionary biology makes informed and relevant contributions at all levels of being human. We now know (as seen in Figure 2 and Figure 3) that the human genital system, both internally and externally, initially forms in the embryo as a single, common system. This means that the typical male and female organs, such as the 12.See: (1) Swaab (2018), (2) Cohen-Kettenis and Gooren (1999), (3) Savic and Arver (2011).

13.This section is based on an article by Jurie van den Heever and Chris Jones (2016). 


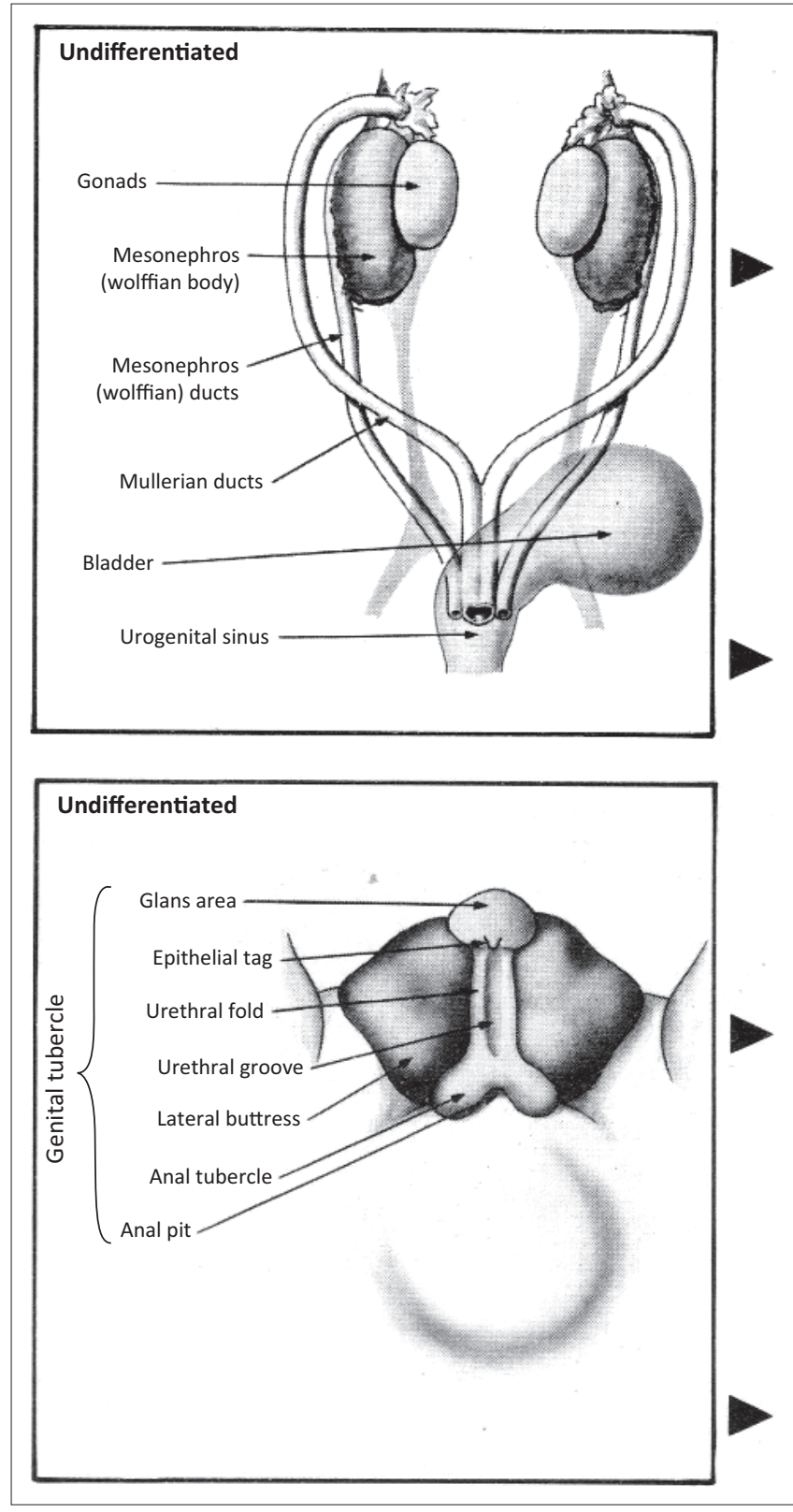

Source: Jost, A.D., 1971, 'Development of sexual characteristics', in Human reproduction From the Science Journal, Special Issue, June 1970, pp. 104-105, Paladin, London.

Note: Differentiation of sexual characteristics. The early embryo grows without showing any sexual characteristics, and the male and female sexual organs eventually develop from common basic structures.

FIGURE 2: The development of the internal genital ducts from the undifferentiated system.

penis and the clitoris, develop from the same, initially sexless tissue, the genital tubercle, and are therefore homologous.

An embryo can therefore develop into either a boy or a girl, and each of us still bears the marks of our common origin. One or even more pairs of non-functional nipples, probably the most useless structures on a man's body, are silent witnesses to this process. Sexuality, in whatever form, is determined prenatally and is consequently something over which the individual has no control.

Except for the fact that some researchers are already talking about five or even more identifiable sexes, Figure 1 - referring
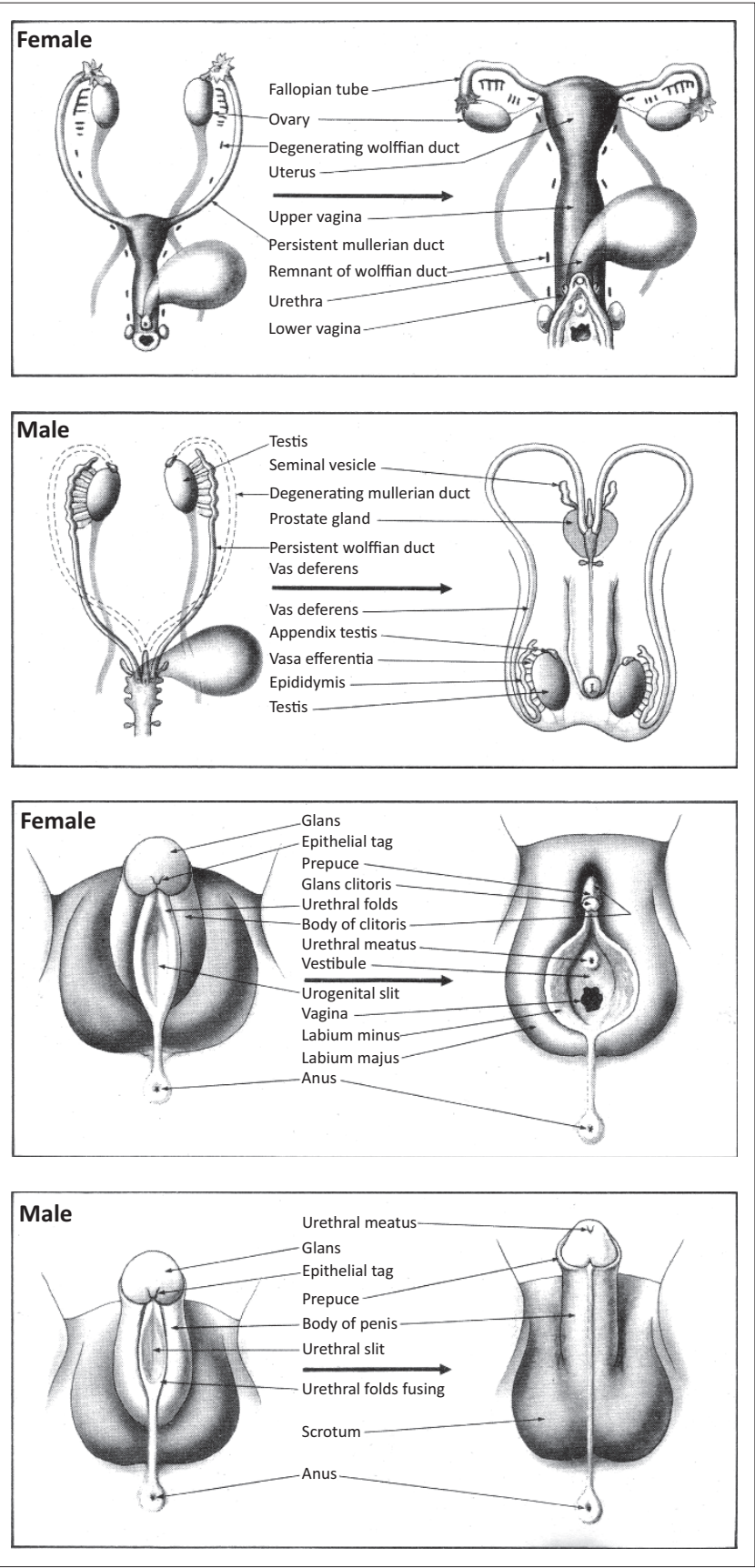

Source: Jost, A.D., 1971, 'Development of sexual characteristics', in Human reproduction, From the Science Journal, Special Issue, June 1970, pp. 104-105, Paladin, London.

FIGURE 3: The development of external genitalia from the genital tubercle.

to the spectrum of human sexual characteristics - incorporates the wide range of diagnostic anatomical and physiological sexual characteristics and shows a continuum of up to 15 transitional stages between a heterosexual man and a heterosexual woman. Human sexuality is predominantly heterosexual but in fact extends over a much broader, varied continuum. People therefore err when the issue of human sexuality is approached merely through the lens of heterosexuality and homosexuality.

Ministers of religion who thus claim to have led a constitutive gay person through prayer to heterosexuality show little understanding of this spectrum of human sexuality. Known as aversion therapy, this technique most often leads to 
spiritual and emotional damage in gay people. Other forms of therapy, including post-natal invasive surgery, appear to be totally ineffective ${ }^{14}$ as well.

Researchers now know, as described above, that the development of an embryo's sexuality can be decisively influenced by the balance between different hormones in the mother's body, the environment in the womb, the birth order of biologically related brothers as well as the composition of the genes. ${ }^{15}$ It brings into play different physiological, anatomical and genetic combinations. Biology as a field of study, and specifically the biology of human beings, is so complex that statements about the nature and essence of a human being can no longer be based solely on biblical statements and holy texts. People who want to do this show that they do not understand that the biological knowledge of the Bible (we refer here to the Bible and Christian religion because this is what we know best) is prescientific and is mostly based on naive observations that are not related to today's reality.

In such a world, bats are birds, ostriches are very bad parents, and the skin colour of unborn livestock can be affected by placing twigs from which the bark has been partially removed at drinking places. The fact of the matter is that the people who wrote the Bible knew nothing of the embryological, anatomical, physiological or genetic information that is common knowledge to contemporary primary schoolchildren. Bible writers were clearly not aware of the full spectrum of human sexuality and so their insights cannot serve as a guide today. To make decisions to the detriment of Lesbian, Gay, Bisexual, Transgender, Intersex, Queer and Other (LGBTIQ+) members on the basis of (amongst other things) some isolated text verses mocks the Bible.

If believers are really serious about the important biblical command that you should love your neighbour as yourself, there is really no way out. Important biological findings can no longer simply be ignored, as in the apartheid years in South Africa. Biology provides indispensable input on the nature and essence of human beings, which is ignored by the church at its own peril. In light of the latest findings, churches should be aware that if they persist in attempting to prohibit LGBTIQ+ people from forming loving, caring civil unions or marriage, church membership or employment, it will be in conflict with rational biological evidence, cannot be justified from the Bible and will not only be a stain on the human dignity of LGBTIQ+ couples and people but a black day for religion. People across the sexual spectrum are each other's fellow human beings or neighbours and must therefore be fully and unconditionally accepted as human beings.

14.See Swaab (2018).

15.See Swaab (2018).

\section{Conclusion}

In this article, based on research by numerous scientists over a long period of time, we focussed on the most important building blocks of sexuality and discussed differences in brain architecture between men and women as determined in the womb. This was followed by a discussion of the 'five sexes' proposal by Anne Fausto-Sterling, the spectrum of human sexual characteristics, as evinced by the various sexual orientations. The article then considered bisexuality and gender identity and expression, concluding with a clear message to religious denominations, specifically Christianity, on how a proper, loving church should engage with the sexual orientations of its members.

\section{Acknowledgements Competing interests}

The authors declare that they have no financial or personal relationships that may have inappropriately influenced them in writing this article.

\section{Authors' contributions}

C.J. and J.v.D.H. both contributed equally to this research article.

\section{Ethical considerations}

This article followed all ethical standards for research without direct contact with human or animal subjects.

\section{Funding information}

This research received no specific grant from any funding agency in the public, commercial or not-for-profit sectors.

\section{Data availability}

Data sharing is not applicable to this article as no new data were created or analysed in this study.

\section{Disclaimer}

The views and opinions expressed in this article are those of the authors and do not necessarily reflect the official policy or position of any affiliated agency of the authors.

\section{References}

Ainsworth, C., 2015, 'Sex redefined', Nature 518(7539), 288-291. https://doi. org/10.1038/518288a

Allen, L.S. \& Gorski, R.A., 1992, 'Sexual orientation and the size of the anterior commissure in the human brain', Proceedings of the National Academy of Sciences of the United States of America 89(15), 7199-7202. https://doi.org/10.1073/ pnas.89.15.7199

American Psychological Association, 2021, Understanding bisexuality, Washington, DC, viewed 26 January 2021, from https://www.apa.org/pi/lgbt/resources/ bisexual.

Arnold, A.P., 2012, 'The end of gonad-centric sex determination in mammals', Trends in Genetics 28(2), 55-61. https://doi.org/10.1016/j.tig.2012.10.004

BBC News, 2017, German parents can register babies as third gender, court rules, 08 November 2017, viewed 25 January 2021, from https://www.bbc.com/news/ world-europe-41912754. 
BBC News, 2019, Germany adopts intersex identity into law, 01 January 2019, viewed 25 January 2021, from https://www.bbc.com/news/world-europe46727611\#: :text=Intersex\%20people $\% 20$ in $\% 20$ Germany $\% 20$ can, new $\% 20$ law $\% 20$ adopted $\% 20$ in $\% 20$ December.\&text $=$ Intersex $\% 20$ people $\% 20$ are $\% 20$ born $\% 20$ with,to $\% 20$ help $\% 20$ recognise $\% 20$ intersex $\% 20$ people.

Cohen-Kettenis, P.T. \& Gooren, L.J., 1999, 'Transsexualism: A review of etiology, diagnosis and treatment', Journal of Psychosomatic Research 46(4), 315-333. https://doi.org/10.1016/S0022-3999(98)00085-3

Colapinto, J., 2006, As nature made him: The boy who was raised as a girl, Harper Perennial, New York, NY.

Copen, C.E., Chandra, A. \& Febo-Vazquez, I., 2016, Sexual behavior, sexual attraction, and sexual orientation among adults aged 18-44 in the United States: Data From the 2011-2013 national survey of family growth, division of vital statistics, National Health Statistics Report, Number 88, January 07, 2016, viewed 26 January 2021, from https://www.cdc.gov/nchs/data/nhsr/nhsr088.pdf.

Couples Guide, Educational Website, 2018-2020, A bit history about brain research viewed 27 January 2021, from https://couples.guide/about/a-bit-history-aboutbrain-research/.

Fausto-Sterling, A., 1993, 'The five sexes: Why male and female are not enough', The Sciences 33(2), 20-24. https://doi.org/10.1002/j.2326-1951.1993.tb03081.x

Fausto-Sterling, A., 2000, 'The five sexes, revisited: The emerging recognition that people come in bewildering sexual varieties is testing medical values and social norms', The Sciences, viewed 28 January 2021, from http://www2.kobe-u.ac. jp/ alexroni/IPD\%202015\%20readings/IPD\%202015_4/FAUSTO_STERLING 2000-The_Sciences $\% 205 \% 20$ sexes $\% 20$ revisited.pdf.

Gellatly, C., 2009, 'Trends in population sex ratios may be explained by changes in the frequencies of polymorphic alleles of a sex ratio gene', Evolutionary Biology 36 190-200. https://doi.org/10.1007/s11692-008-9046-3

Gershoni, M. \& Pietrokovski, S., 2017, 'The landscape of sex-differential transcriptome and its consequent selection in human adults', BMC Biology 15, 7. https://doi. org/10.1186/s12915-017-0352-z

Graves, J., 2017, The genetic differences between men and women could be greater than we thought, 06 November 2017, World Economic Forum, Davos, viewed 27 January 2021, from https://www.weforum.org/agenda/2017/11/throughout-ourbodies-thousands-of-genes-act-differently-in-men-and-women/.

Jordan, B.K., Mohammed, M., Ching, S.T., Délot, E., Chen, X., Dewing, P. et al., 2001, 'Upregulation of WNT-4 signaling and dosage-sensitive sex reversal in humans', American Journal of Human Genetics 68(5), 1102-1109. https://doi.org/10.1086/320125

Jost, A.D., 1971, 'Development of sexual characteristics', in Human reproduction From the Science Journal, Special Issue, June 1970, pp. 104-105, Paladin, London.

Kessler, S., 1998, Lessons from the intersexed, Rutgers University Press, New Brunswick.

Kinsey, A.C., Pomeroy, W.R. \& Martin, C.E., 1948, Sexual behavior in the human male, Indiana University Press, Bloomington, IN.
LeVay, S., 1991, 'A difference in hypothalamic structure between heterosexual and homosexual men', Science 253(5023), 1034-1037. https://doi.org/10.1126/ science.1887219

MedlinePlus, 2021, Intersex, U.S. National Library of Medicine, viewed 16 February 2021, from https://medlineplus.gov/ency/article/001669.htm.

Moir, A. \& Jessel, D., 1989, Brainsex: The real difference between men \& women, Arrow Books, London.

Navarro, J.C. \& Tewksbury, R., 2015, 'Bestiality: An overview and analytic discussion', Sociology Compass 9(10), 864-875. https://doi.org/10.1111/soc4.12306

Pearsall, P., 2001, Partners in pleasure: Sharing success, creating joy, fulfilling dreams Together, Hunter House Publishers, Alameda, CA

Rahman, M.S. \& Pang, M.G., 2020, 'New biological insights on $X$ and $Y$ chromosomebearing spermatozoa', Frontiers in Cell and Developmental Biology 7, 388. https:// doi.org/10.3389/fcell.2019.00388

Restak, R., 1979, The brain: The last frontier, Doubleday and Company, New York, NY.

San Francisco Human Rights Commission, LGBT Advisory Committee, 2011, Bisexual invisibility: Impacts and recommendations, viewed 26 January 2021, from https:// sf-hrc.org/sites/default/files/Documents/HRC Publications/Articles/Bisexual Invisiblity_Impacts_and_Recommendations_March_2011.pdf.

Savic, I. \& Arver, S., 2011, 'Sex dimorphism of the brain in male-to-female transsexuals', Cerebral Cortex 21(11), 2525-2533. https://doi.org/10.1093/ cercor/bhr032

Shettles, L.B., 1960, 'Nuclear morphology of human spermatozoa', Nature 186, 648-649. https://doi.org/10.1038/186648a0

Statement of the American Psychological Association Regarding Pedophilia and the Diagnostic and Statistical Manual of Mental Disorders (DSM-5), 1993, American psychological association, viewed 03 February 2021, from https://www.apa.org/ news/press/releases/2013/10/pedophilia-mental.

Swaab, D., 2018, Ek is my brein: Van baarmoeder tot Alzheimer, Protea Boekhuis, Pretoria.

Swaab, D.F. \& Hofman, M.A., 1990, 'An enlarged suprachiasmatic nucleus in homosexual men', Brain Research 537(1-2), 141-148. https://doi.org/10. 1016/0006-8993(90)90350-K

Trabzuni, D., Ramasamy, A., Imran, S., Walker, R., Smith, C., Weale, M.E. et al., 2013, 'Widespread sex differences in gene expression and splicing in the adult human brain', Nature Communications 4, 2771. https://doi.org/10.1038/ncomms3771

United Nations Human Rights Office of the High Commissioner, n.d., Intersex, Free and Equal, United Nations for LGBT Equality, pp. 1-2, viewed 25 January 2021, from https://www.unfe.org/wp-content/uploads/2017/05/UNFE-Intersex.pdf.

Van den Heever, J. \& Jones, C. 2016, 'Meer eenders as anders', Netwerk24, viewed 25 January 2021, from https://www.netwerk24.com/Stemme/Aktueel/meereenders-as-anders-20161119.

Zhao, F., Franco, H.L., Rodriquez, K.F., Brown, P.R., Tsai, M., Tsai, S.A. et al., 2017, 'Elimination of the male reproductive tract in the female embryo is promoted by COUP-TFIl in mice', Science 357(6352), 717-720. https://doi.org/10.1126/science.aai9136 